\title{
Morphology and morphometry of ramification of the aortic arch in domestic shorthair cats in the clinical aspect
}

\author{
KAROLINA BARSZCZ, JOANNA KLEĆKOWSKA-NAWROT*, \\ KAROLINA GOŹDZIEWSKA-HARŁAJCZUK*, ZBIGNIEW BEŁKOT**, NORBERT CZUBAJ, \\ WOJCIECH SOKOŁOWSKI, MAŁGORZATA DZIERZĘCKA, DAWID JAŃCZAK***
}

\author{
Department of Morphological Sciences, Faculty of Veterinary Medicine, \\ Warsaw University of Life Sciences - SGGW, Nowoursynowska 159, 02-776 Warsaw, Poland \\ *Department of Animal Physiology and Biostructure, Faculty of Veterinary Medicine, \\ Wroclaw University of Environmental and Life Sciences, Kożuchowska 1/3, 51-631 Wroclaw, Poland \\ ${ }^{* *}$ Department of Food Hygiene of Animal Origin, Faculty of Veterinary Medicine, \\ University of Life Sciences in Lublin, Akademicka 12, 20-950 Lublin, Poland \\ ***Division of Parasitology, National Institute of Public Health - National Institute of Hygiene, \\ Chocimska 24, 00-791 Warsaw, Poland
}

Barszcz K., Klećkowska-Nawrot J., Goździewska-Harłajczuk K., Bełkot Z., Czubaj N., Sokołowski W., Dzierzęcka M., Jańczak D. Morphology and morphometry of ramification of the aortic arch in domestic shorthair cats in the clinical aspect

\section{Summary}

The aim of the study was to investigate the morphology and morphometry of ramifications of the aortic arch in domestic shorthair cats in relation to the sex of the animals. The morphological study was performed on 61 hearts of adult domestic shorthair cats of both sexes, preserved in the $10 \%$ solution of formalin. Measurements of the area of openings of basic branches and distances between them were performed. In cats we can observe a double type of direct ramification of the aortic arch: the brachiocephalic trunk and the left subclavian artery. In all studied cases, the surface area of the ostium of the brachiocephalic trunk (SABT) was greater $4.94 \pm 1.35 \mathrm{~mm}^{2}$ than the surface area of the ostium of the left subclavian artery (SALSA) $2.38 \pm 0.88 \mathrm{~mm}^{2}$. The average difference between the opening area of the above vessels (r) amounted to $2.56 \mathrm{~mm}^{2}$. In the studied group of cats, the distance between the openings (d) varied between 0.5 and $4.37 \mathrm{~mm}$. In the post hoc comparison of the mean values no statistically significant differences were found between the population of males and females. Fundamental changes in the structure of openings were found in two females. The first one concerned a secondary division of the brachiocephalic trunk opening and the second one - a secondary division of the opening of the left subclavian artery in the area of their parting from the aortic arch. CT angiography or MRI angiography is the method of choice for diagnosis of vascular disorders or malformations. The knowledge of the aortic arch morphology in various species of animals is a prerequisite for a correct assessment of the results of imaging tests.

Keywords: domestic shorthair cat, aortic arch, left subclavian artery, brachiocephalic trunk

The morphology of the aortic arch and its branches is noteworthy both in humans and in animals. This is due to the occurrence of congenital malformations of this part of the aorta, as well as of disorders in the topography of the adjacent organs. They may take an isolated form or occur as a complex defects of the heart and vessels. Some common anomalies reported in humans include: DAA - a double aortic arch, ARSA
- aberrant right subclavian artery, right sided aortic arch, interrupted aortic arch and DLAA - double lumen aortic arch $(1,6)$. In animals, the most commonly reported anomaly is a DAA, e.g. in cats $(25,30)$ and $\operatorname{dogs}(10,19)$.

Constant development of diagnostic imaging increases the effectiveness of cardiovascular disorders diagnosis. In veterinary medicine, computed tomo- 
graphy $(\mathrm{CT})$ and magnetic resonance (MR) are increasingly used for diagnostic purposes $(7,13)$. Due to the lower cost and relatively easy testing, access to CT in veterinary medicine is increasing rapidly. Computed tomography enables acquiring images of sections of the examined specimen without the superimposition of organs. Modern, multi-row units provide high contrast image quality with detailed anatomy of a patient. CT angiography with intravenous contrast application together with multiplanar reconstruction (showing the studied structure in any chosen plane) and 3D reconstruction allows practitioners to evaluate blood vessel diseases with any related pathologies $(14,27)$. The analysis of thus obtained images requires knowledge of clinical anatomy. Descriptions of the morphology of the aortic arch and its branches in the domestic cat may be found mainly in academic textbooks and atlases of anatomy $(9,12,17,26)$. Detailed anatomical studies on the morphology and morphometry of the aortic arch branches are essential to provide reliable data for practitioners using advanced imaging modalities as CT and MRI. The aim of the study was therefore to investigate the morphology and morphometry of ramifications of the aortic arch in domestic shorthair cats in relation to sex of animals.

\section{Material and methods}

The study was conducted on 61 adult domestic shorthair cats of both sexes (29 males, 32 females), of the average body weight of $3.98 \mathrm{~kg}$, aged from 2 to 13 years (28). The animals were euthanized by veterinarians of the Small Animal Clinic of the Faculty of Veterinary Medicine, Warsaw University of Life Sciences. The animals were not killed for the purpose of this study. The animals presented to the clinic were euthanized under general anesthesia by an overdose of barbiturates with the owners' consent for various non-cardiac reasons. The anaesthetic was administered via a peripheral intravenous catheter. The owners of the animals also consented to the use of the cadavers for scientific purposes. According to Polish law, the post mortem use of tissues does not require an approval from the Ethics Committee (24). Pathological examination of the whole body was performed before the dissection of the hearts.

Each heart was dissected from the specimen and rinsed with tap water to remove blood. This was followed by an anatomical preparation for the visualization of the aortic arch and the related vessels (Fig. 1). In the next stage, the main vascular trunks were cut crosswise showing the ostium of the brachiocephalic trunk and the left subclavian artery. The obtained tissues were further fixed in $10 \%$ formalin and $0.25 \%$ ethanol. Before the measurements were taken, the treated surfaces were dried with filter paper and a mechanical aspirator. Morphological studies were performed with the use of ECLERIS (HALOLUX 150, Ecleris USA Inc., San Diego, USA) surgical microscope with an integrated video channel and software adapted to metric analyses of images (AxioVision Rel. 4.7, Carl Zeiss MicroImaging $\mathrm{GmbH}$, Jena, Germany). Out of 61 cats, the measurements were performed on 59 specimens. In the other 2 specimens, the measurements were not taken due to differences in the structure of ostia. The following morphometric parameters were analysed: $\mathrm{SA}_{\mathrm{BT}}$ - the surface area of the ostium of the brachiocephalic trunk $\left(\mathrm{mm}^{2}\right) ; \mathrm{SA}_{\mathrm{LSA}}$ - the surface area of the ostium of the left subclavian artery $\left(\mathrm{mm}^{2}\right) ; \mathrm{r}$ - the difference between $\mathrm{SA}_{\mathrm{BT}}$ and $\mathrm{SA}_{\mathrm{LSA}}\left(\mathrm{mm}^{2}\right) ; \mathrm{d}$ - distance between the individual ostia of vessels $(\mathrm{mm})$.

The statistical analysis was performed applying STATISTICA 12 software (StatSoft, Inc. Tulsa, USA). The differences between the population of males and females for each of the parameters were determined by the Fisher's LSD test with the significance level at $\mathrm{p} \leq 0.05$.

\section{Results and discussion}

In all studied specimens $(n=61)$, the double type of direct branches from the aortic arch was found. This means that two arteries arose from the mentioned structure: the brachiocephalic trunk and the left subclavian artery (Fig. 1, 2).

In all studied cases, the $\mathrm{SA}_{\mathrm{BT}}$ was greater $(4.94 \pm$ $\left.1.35 \mathrm{~mm}^{2}\right)$ than the $\mathrm{SA}_{\mathrm{LSA}}\left(2.38 \pm 0.88 \mathrm{~mm}^{2}\right)$, without differences between the population of males and females (Tab. 1). The mean values of these parameters in both sexes were very similar, and in terms of the difference (r) between the surface areas of the ostia of these arteries, they were even identical. Noticeably, in 4 cases, the difference between these parameters was less than or equal to $1.0 \mathrm{~mm}^{2}$ (Fig. 2B). However, in

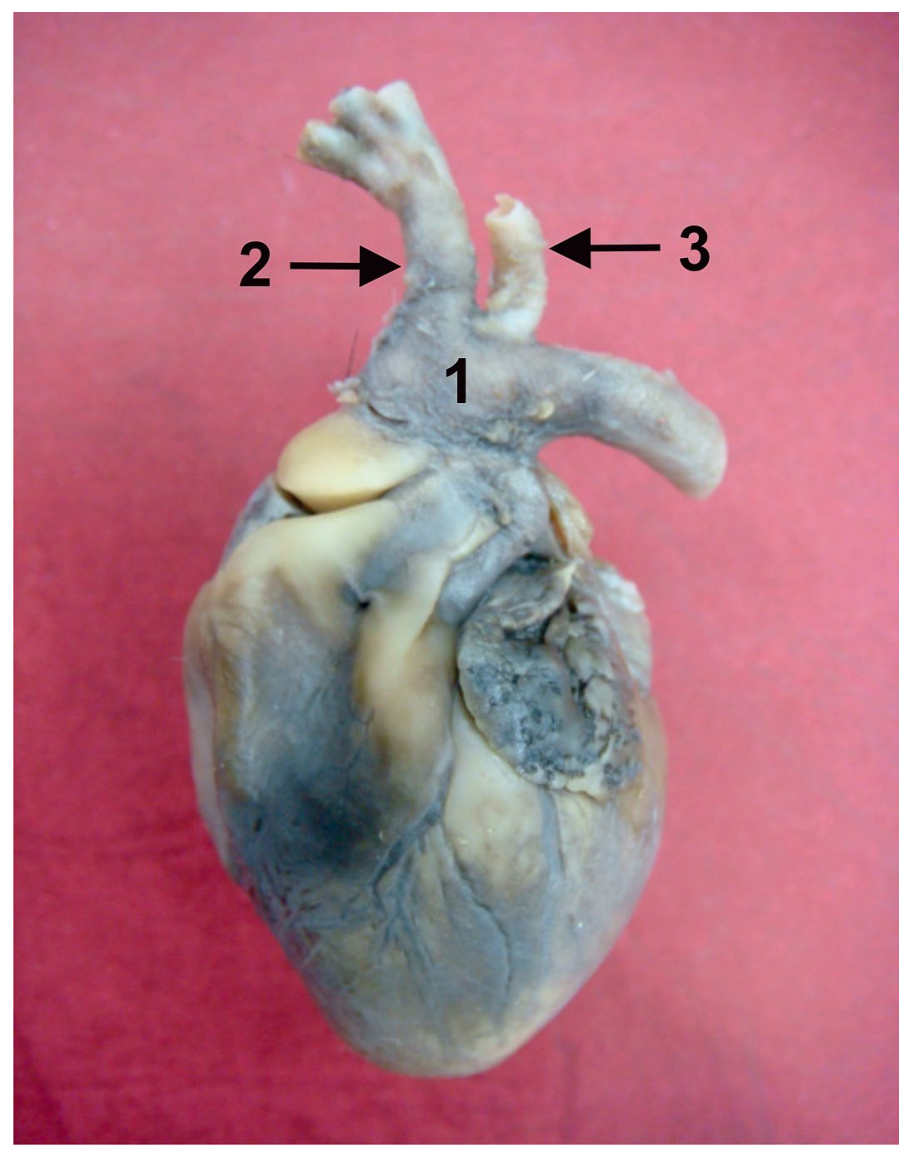

Fig. 1. Auricular surface of the heart. Ramification of the aortic arch

Explanations: 1 - aortic arch; 2 - brachiocephalic trunk; 3 - left subclavian artery 
7 individuals the difference between the surface area of the ostia of both arteries exceeded $4.0 \mathrm{~mm}^{2}$, and in one female this measurement even reached $5.12 \mathrm{~mm}^{2}$

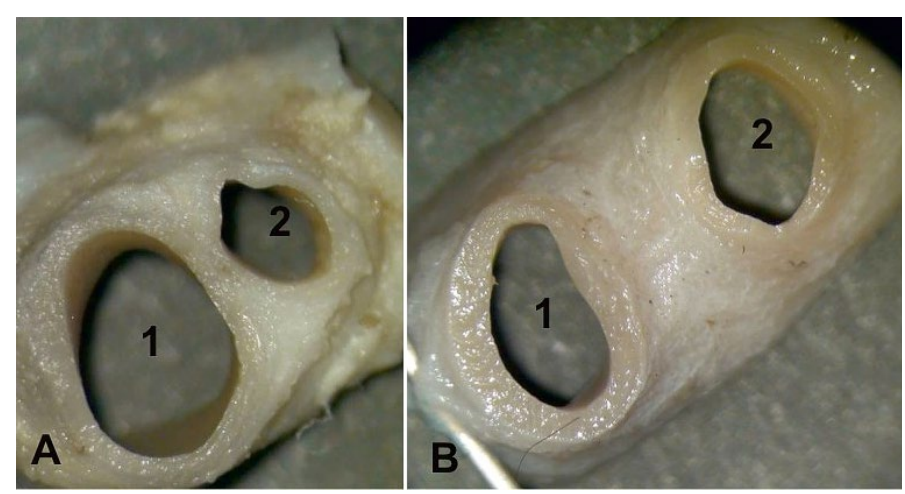

Fig. 2. Aortic arch (transverse section through the main trunks)

Explanations: 1 - brachiocephalic trunk; 2 - left subclavian artery

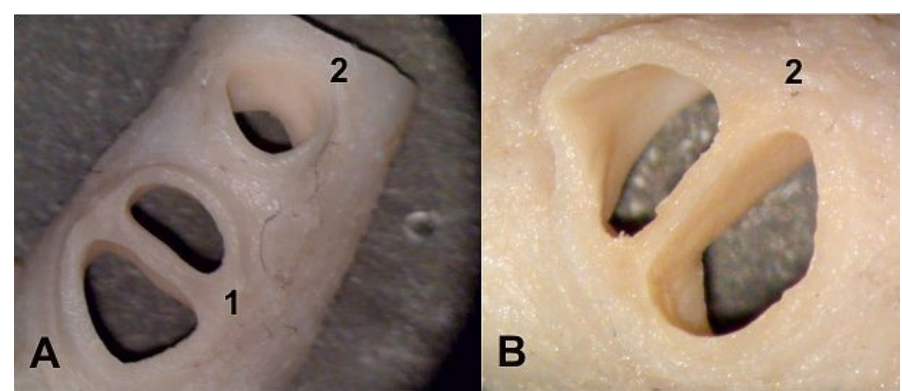

Fig. 3. Aortic arch (transverse section through the main trunks)

Explanations: A - secondary division of the brachiocephalic trunk opening; B - secondary division of the opening of the left subclavian artery; 1 - brachiocephalic trunk; 2 - left subclavian artery

Tab. 1. The level of parameters studied in relation to the sex of cats

\begin{tabular}{|c|c|c|}
\hline Parameters & Males & Females \\
\hline $\begin{array}{l}S A_{\mathrm{BT}} \\
\text { Mean } \\
\text { SD } \\
\text { Min } \\
\text { Max }\end{array}$ & $\begin{array}{l}4.95^{\mathrm{a}} \\
1.31 \\
2.60 \\
7.86\end{array}$ & $\begin{array}{l}4.92^{\mathrm{a}} \\
1.40 \\
2.78 \\
8.07\end{array}$ \\
\hline $\begin{array}{l}\mathrm{SA}_{\text {LSA }} \\
\text { Mean } \\
\text { SD } \\
\text { Min } \\
\text { Max }\end{array}$ & $\begin{array}{l}2.42^{\mathrm{a}} \\
0.91 \\
1.10 \\
5.43\end{array}$ & $\begin{array}{l}2.33^{a} \\
0.86 \\
1.01 \\
4.39\end{array}$ \\
\hline $\begin{array}{ll} & \\
\text { Mean } & \\
\text { SD } \\
\text { Min } \\
\text { Max }\end{array}$ & $\begin{array}{l}2.53^{\mathrm{a}} \\
1.02 \\
0.31 \\
4.72\end{array}$ & $\begin{array}{l}2.59^{a} \\
1.05 \\
0.99 \\
5.12\end{array}$ \\
\hline $\begin{array}{ll}\text { d } & \\
\text { Mean } \\
\text { SD } \\
\text { Min } \\
\text { Max }\end{array}$ & $\begin{array}{l}2.24^{\mathrm{a}} \\
0.61 \\
1.14 \\
3.65\end{array}$ & $\begin{array}{l}2.23^{a} \\
0.68 \\
0.50 \\
4.37\end{array}$ \\
\hline
\end{tabular}

Explanations: a - means with superscript the same letter does not differ significantly at $\mathrm{p} \leq 0.05 ; \mathrm{SA}_{\mathrm{BT}}-$ the surface area of the ostium of the brachiocephalic trunk $\left(\mathrm{mm}^{2}\right) ; \mathrm{SA}_{\mathrm{LA}}$ - the surface area of the ostium of the left subclavian artery $\left(\mathrm{mm}^{2}\right) ; \mathrm{r}$ - difference between $\mathrm{SA}_{\mathrm{BT}}$ and $\mathrm{SA}_{\mathrm{LSA}}\left(\mathrm{mm}^{2}\right) ; \mathrm{d}$-distance between the individual ostia of vessels $(\mathrm{mm})$
(Fig. 2A). No differences were recorded between the population of males and females.

The distance between the ostium of the brachiocephalic trunk and the ostium of the left subclavian artery (d) in males and females reached similar values without differences between the population of males and females. Both ostia were rather close to each other, on average at $2.24 \pm 0.61 \mathrm{~mm}$ in males and $2.23 \pm 0.68$ $\mathrm{mm}$ in females (Fig. 2A). In one female specimen it reached $4.37 \mathrm{~mm}$ (Fig. 2B, Tab. 1).

In the case of two females, the assessment of the investigated parameters was not conducted. This was due to the secondary division of the brachiocephalic trunk and the left subclavian artery, taking place directly in their ostia (Fig. 3).

Descriptions of the morphology of individual sections of the aorta have been featured in numerous veterinarian publications $(3,4,8,9,17,18,21,26,29)$. In domestic mammals two types of direct branches of the aortic arch can be distinguished. In the first one the only branch present is the brachiocephalic trunk. It is described in ruminants and in horses $(9,17,26)$. In the second type two vessels arise independently from the ascending aorta: the brachiocephalic trunk and the left subclavian artery. This type can be observed in carnivores, domestic pigs, brown hares, paca, chinchillas and guinea-pigs $(5,9,12,16,17,22,23,26)$.

Studies conducted by Atalar et al. (2) on porcupines revealed the presence of three vessels originating from the aortic arch. The largest branch is the brachiocephalic trunk. In close proximity arises the left common carotid artery. The third branch is the left subclavian artery, the diameter of which is significantly smaller than of the brachiocephalic trunk.

In birds, a characteristic feature is the lack of branches of the aortic arch and the above mentioned vessels originate from the ascending aorta. In humans the aortic arch has three branches, namely, the brachiocephalic trunk, the left common carotid artery and the left subclavian artery. There are many publications on this topic in humans. The observed variations of the branching pattern of the aortic arch relate to their number, course and the area of their origination. Some cases are described where the number of vessels varied from 1 to even $6(9,15,20)$.

In most of these papers, the authors only determine the individual vessel syntopy based on morphological and angiographic studies.

The available literature provides only one publication on the detailed morphology of the brachiocephalic trunk in a domestic cat (11). The conducted study showed the presence of three types of branches of the said vessel. In the most common type, present in 29 out of 56 specimens, two vessels arise from the brachocephalic trunk: namely, the left common carotid artery and the common branch for the right subclavian artery and the right common carotid artery. The second most common (21 individuals) was the type specified 
by the authors as trifurcate. In these individuals the three vessels: the right subclavian artery and the left and right common carotid artery each had separate ostia. In the cited publication, the authors describe the distance between the ostia of the vessels arising from the aortic arch. The longest one was $1.75 \mathrm{~cm}$. In the present study it was noticed that the distance between the brachiocephalic trunk and the left subclavian artery varies from 0.5 to $4.37 \mathrm{~mm}$. The difference can be explained by the different cat population that was investigated.

CT angiography or MR angiography is the method of choice for diagnosis of vascular disorders or malformations $(13,14,27)$. The knowledge of the variations of aortic arch morphology in various species of animals is a prerequisite for a correct assessment of the results of imaging tests.

\section{References}

1. Aleszewicz-Baranowska, J., Sabiniewicz R., Chojnicki M.: Podwójne światło łuku aorty a podwójny łuk aorty. Folia Cardiol. 2006, 13, 164-167.

2. Atalar Ö., Yilmaz S., Burma O., Ilkay E.: The macroanatomical investigations on the aortic arch in porcupines (Hystrix cristata). Anat. Histol. Embryol. 2003, 32, 367-369

3. Barszcz K., Kupczyńska M., Klećkowska-Nawrot J., Skibniewski M., Janczyk P.: Morphology of coronary ostia in domestic shorthair cat. Anat. Histol. Embryol. 2016, 45, 81-87.

4. Bartyzel B. J., Charuta A., Barszcz K., Koleśnik A., Kobryń H.: Morphology of the aortic valve of Gallus gallus f. domestica. Bull. Vet. Inst. Pulawy 2009, 53, 147-151.

5. Brudnicki W., Macherzyńska A., Nowicki W.: Variation in the arteries of the aortic arch in european brown hare (Lepus europaeus). EJPAU 2007, 10, 1 http://www.ejpau.media.pl/volume10/issue1/art-03.html

6. Budziszewska P., Kuka D., Sadowski M., Sadowski K., Jeanty P., Skrzypulec V.: Podwójny łuk aorty: opis przypadku. Ginekol. Pol. 2009, 80, 712-715.

7. Contreras S., Vázquez J. M., Miguel A., Morales M., Gil F., López O., Arencibia A.: Magnetic resonance angiography of the normal canine heart and associated blood vessels. Vet. J. 2008, 178, 130-132.

8. Dabanoğlu I.: A quantitative study of the aorta of the New Zealand rabbit (Oryctolagus cuniculuc L.). Anat. Histol. Embryol. 2000, 29, 145-147.

9. Dyce K. M., Sack W. O., Wensing C. J. G.: Textbook of Veterinary Anatomy. Saunders, Philadelphia 2010.

10. Ferrigno C. R., Ribeiro A. A., Rahal S. C., Orsi A. M., Fioreto E. T., Castro M. F., Mchado M. R., Singaretti F.: Double aortic arch in a dog (Canis familiaris): a case report. Anat. Histol. Embryol. 2001, 30, 379-381.

11. Gonzalez V. H., Ball S., Cramer R., Smith A.: Anatomical and morphometric variations in the arterial system of the domestic cat. Anat. Histol. Embryol. 2015, 44, 428-432.

12. Habermehl K. H.: Herz, [in:] Frewein J., Vollmerhaus B. (eds): Anatomie von Hund und Katze, Blackwell Wissenschafts-Verlag, Berlin 1994.

13. Hecht S., Durant A. M., Adams W. H., Conklin G. A.: Use of contrast-enhanced MR angiography (CE-MRA) for diagnosis of vascular ring anomaly in a dog. Hindawi Publishing Corporation Case Reports in Veterinary Medicine, http:// dx.doi.org/10.1155/2012/316530 2012

14. Henjes C. R., Nolte I., Wefstaedt P.: Multidetector-row computed tomography of thoracic aortic anomalies in dogs and cats: Patent ductus arteriosus and vascular rings. BMC Veterinary Research 2011, 7, 57.

15. Jakubowicz M., Ratajczak W., Nowik M.: Aberrant left subclavian artery. Folia Morphol. 2002, 61, 53-56.

16. Kabak M., Haziroglu R. M.: Subgross investigation of vessels originating from arcus aortae in guine-pig (Cavia porcellus). Anat. Histol. Embryol. 2003, 32, 362-366

17. König H. E., Liebich H.-G.: Veterinary Anatomy of Domestic Mammals. Schattauer, Stuttgart 2007.

18. Kupczyńska M., Barszcz K., Olbrych K., Polguj M., Wysiadecki G., Topol M., Klećkowska-Nawrot J.: Coronary arteries of the European bison (Bison bonasus). Acta Vet. Scand. 2015, 57, 82.
19. Moonan N., Mootoo N. F., Mahler S. P.: Double aortic arch with a hypoplastic left arch and patent ductus arteriosus in a dog. J. Vet. Cardiol. 2007, 9, 59-61.

20. Nelson M. L., Sparks C. D.: Unusual aortic arch variation: distal origin of common carotid arteries. Clinical Anatomy 2001, 14, 62-65.

21. Ocal M. K., Mutus R., Corekci I., Daglioglu S.: A quantitative study of the aorta of the chicken (Gallus domesticus). Anat. Histol. Embryol. 1997, 26, 203-205.

22. Oliveira F. S., Machado M. R. F., Miglino M. A., Nogueira T. M.: Gross anatomical study of the aortic ARC branches of the paca (Agouti paca, Linnaeus, 1766). Braz. J. Vet. Res. Anim. Sci. 2001, 38, 103-105.

23. Ozdemir V., Cevik-Demirkna A., Türkmenoğlu I.: Subgross and macroscopic investigation of blood vessels originating from aortic arch in the chinchilla (Chinchilla lanigera). Anat. Histol. Embryol. 2008, 37, 131-133.

24. Parliament of the Republic of Poland: Ustawa z dnia 21 sierpnia 1997 o ochronie zwierząt. Dz. U. 1997 Nr 111 poz. 724 z późn. zmianami. 2012.

25. Ricardo C., Augusto A., Canavese S., Marcos A., Ticona E., Fernandes M., Rita M., Singareti F.: Double aortic arch in a dog (Canis familiaris): a case report. Anat. Histol. Embryol. 2001, 30, 379-381.

26. Schaller O.: Illustrated Veterinary Anatomical Nomenclature. MVS Medizinverlage Stuttgart GmbH \& Co., Stuttgart 2007.

27. Schwarz T., Saunders J.: Veterinary Computed Tomography. Wiley-Blackwell, Oxford 2011.

28. Wąsowicz M., Kupczyńska M., WielądekA., Barszcz K.: Morphometric analysis of occipital bone in the domestic cat in comparison with selected skull size parameters and with special regard to skull morphotype Pol. J. Vet. Sci. 2009 $12,251-258$.

29. World Association of Veterinary Anatomists: Nomina Anatomica Veterinaria Hannover, Germany 2012. http://www.wava-amav.org/Downloads/nav_2012. pdf

30. Yarim M., Gültiken M. E, Öztürk S., Sahal M., Bumin A.: Double aortic arch in a Siamese cat. Vet. Pathol. 1999, 36, 340-341.

Corresponding author: Dr Karolina Barszcz, Ph.D., Department of Morphological Sciences, Faculty of Vet. Med. SGGW, Nowoursynowska 159, 02-776 Warsaw, Poland; e-mail: karolina.barszcz@onet.eu 